\title{
CORRECTION
}

\section{Correction to: Floral temperature patterns can function as foral guides}

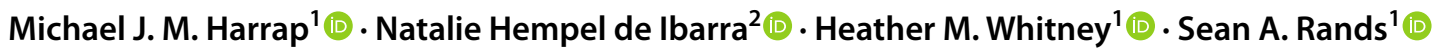

Published online: 7 May 2021

(c) Springer Nature B.V. 2021

\section{Correction to: \\ Arthropod-Plant Interactions (2020) 14:193-206 \\ https://doi.org/10.1007/s11829-020-09742-z}

The acknowledgement section is revised in the original publication of the article.

The correct version of acknowledgement is given below.

Acknowledgement We are grateful to Edward Straw for his work in manipulating and recording the behaviour of a subset of the bee behavioural data, and for his assistance in generating and choosing between the considered reflectance spectra. We also thank Cara Doyle for her technical assistance in the laboratory, and to Nathan Masters for advice with spectrometry.
Publisher's Note Springer Nature remains neutral with regard to jurisdictional claims in published maps and institutional affiliations.

The original article can be found online at https://doi.org/10.1007/ s11829-020-09742-z.

Michael J. M. Harrap

m.j.m.harrap@gmail.com

Natalie Hempel de Ibarra

n.hempel@exeter.ac.uk

Heather M. Whitney

heather.whitney@bristol.ac.uk

Sean A. Rands

sean.rands@bristol.ac.uk

1 School of Biological Sciences, University of Bristol, 24 Tyndall Ave, Bristol BS8 1TQ, UK

2 Centre for Research in Animal Behaviour, University of Exeter, Exeter, UK 